\title{
GEOMETRY FunCTIONS FOR EDGE CRACKS IN STEEL BRIDGE UNDER THREE- AND FOUR- POINT BENDING WITH VARIOUS SPAN
}

\author{
Stanislav SEITL ${ }^{1}$, Petr MIARKA ${ }^{1,2}$, Zdenek KALA ${ }^{2}$ \\ ${ }^{1}$ Institute of Physics of Materials, Academy of Sciences of the Czech Republic, \\ Zizkova 22, 61662 Brno, Czech Republic \\ ${ }^{2}$ Faculty Civil Engineering, Brno University of Technology, \\ Veveri 331/95, 60200 Brno, Czech Republic \\ $\underline{\text { seitl@ipm.cz, Petr.Miarka@vut.cz, kala.z@,fce.vutbr.cz }}$
}

DOI: $10.31490 /$ tces-2018-0015

\begin{abstract}
Fatigue cracks are found during the regular structural inspections. To precisely describe/suggest propagation offatigue cracks throughout structure and it's designed service life, the knowledge of geometry functions describing the stress situation in front of the crack tip for relative crack lengths are important. The cracks usually propagate/initiated from the edge or the surface of the structural element, where the maximum value of applied load is achieved. The theoretical model of fatigue crack propagation is based on linear fracture mechanics (Paris law). Steel structural elements are subjected to various bending load (three-, four-point bending and pure bending etc.). The geometry functions for the edge cracks are calculated for various span according to real steel bridge elements and appropriate polynomial functions independent on the distance are proposed for three- and four-point bending load.
\end{abstract}

\section{Keywords}

Fracture mechanics, 3PB, 4PB, geometry function, stress intensity factor, edge crack.

\section{Introduction}

Fatigue failure is one of the major problems of civil engineering structures, such as railway roads, steel bridges structures or its elements, onshore or logistics structures, etc. Especially, three- or four- point bending cycles during cars, trucks and trains transportation cause many loadings and unloading cycles during the service lifetime (high cyclic fatigue damage). This usually leads to penetration of a fatigue edge crack at the maximum loading point.
Detection of structural damage depends on applied technics, but for large structures like steel bridges (typical dimensions of load bearing structures can have length up to $30 \mathrm{~m}$ long with width to $3 \mathrm{~m}$ height, see [1]) the used equipment, usually detects cracks with length from 5 up to $25 \mathrm{~mm}$.

Prediction of fatigue structure behaviour is implemented to various software e.g. FCProbCalc (Fatigue Crack Probability Calculation). Fatigue progression of the cracks from the edge and from the surface is used as a basis for proposing a system of inspections of details, which tend to be damaged by fatigue [2],[3],[4], sensitivity analysis [5][6], probabilistic analysis of the S-N field [7],[8] and crack propagation rate [9] etc. The input data are usually material properties [10],[11],[12],[13],[14] and information about boundary conditions-calibration curves [15].

Geometry functions for laboratory specimens are mentioned in the following references from relatively easy geometries up to complex geometries in handbooks by Tada et. al [16], Bakker [17] and Murakami [18]. These handbooks use a normative description of the crack growth by using geometry functions based on a relative crack length ratio $\alpha=a / W$, where $a$ is the crack length and $W$ is the specimen's width. To take into account various span $(S)$ to width $(W)$ ratio, literature offers calculation of geometry function for various ratios of $S / W$ ratio.

A boundary-value-collocation procedure was applied to determine values of stress intensity factor (SIF) for single-edge cracks in three-point bending specimen for ratio $a / W$ up to 0.5 and $S / W$ equal to 4 and 8 by Gross and Srawley 1965 [19].

Values of stress intensity factor for pure bending applied in various distance (ratio $H / W=1.5$ to 0.4 ) was calculated by using weight function, such results are 
presented by Fett 1998 [20].

In analysis by Seitl et al. 2017 [15], numerical solution for relatively short cracks ( $a / W$ varies from 0.05 to 0.3 ) is presented.

In this presented paper, the geometry functions for the short edge cracks are proposed for several load regimes and real ratio of width/span of steel bridges. In this analysis, numerical solution for relatively short edge cracks $(a / W$ from 0.01 to 0.5$)$ is presented. This study proves the significance of description of the geometry functions for the possible range of various bending fatigue loads. Appropriate polynomial functions independent on the distance are suggested for TPB and FPB load in case of used ratios $S / W$ (width/span).

\section{Theoretical background}

In order to describe the crack propagation, the linear elastic fracture mechanics based on the Williams' expansion for stationary crack [21] or later for bending stress distribution for stationary crack [22] is typically applied. Paris' law (also known as the Paris-Erdogan law) relates the stress intensity factor range to sub-critical crack growth under the fatigue stress regime [23] and [24]. As such, it is the most popular fatigue crack growth model [25] used in materials science and fatigue fracture mechanics. The basic formula reads:

$$
\frac{\mathrm{d} a}{\mathrm{~d} N}=C(\Delta K)^{m}
$$

where $a$ is the crack length, $N$ is the number of loading cycles and $\mathrm{d} a / \mathrm{d} N$ is the crack propagation rate, which denotes the crack growth for a load cycle. On the right hand side of the equation (1) $C, m$ are the material's constants (dependent on environment, stress ratio, etc.), and $\Delta K$ is the range of the stress intensity factor in front of the crack tip during the fatigue cycle and it is defined as follow:

$$
\Delta K=\Delta \sigma \sqrt{\pi a} f(a / W),
$$

where $\Delta \sigma$ is the constant stress range (the value of $\Delta \sigma$ corresponding to each way of loading is shown in Fig. 1.), $a$ is the crack length and $f(a / W)$ is the geometry function, which represents various boundary conditions.

Tab. 1: Overview of calculation of stress range from applied load type.

\begin{tabular}{|c|c|c|c|}
\hline Load type & Pure bending & $3 \mathrm{~PB}$ & $4 \mathrm{~PB}$ \\
\hline $\begin{array}{c}\text { Stress range } \\
\Delta \sigma\end{array}$ & $\frac{6 M}{W^{2} B}$ & $\frac{3 P S}{2 W^{2} B}$ & $\frac{2 P S}{W^{2} B}$ \\
\hline
\end{tabular}

\section{Boundary conditions of applied load}

The investigated behavior of structural element was loaded with three types of bending loads i.e. pure bending (M), three-point bending (TPB) [26] and four-point bending (FPB). The load states are shown in Fig. 1.

According to [1] a span of a single supported steel beams can vary from 30 to $40 \mathrm{~m}$ and continuously supported beams can have span up to $50 \mathrm{~m}$ in some extreme cases even $150 \mathrm{~m}$. Based on these values of span an empirical estimation of the beam's width (height) can be done. Estimation of width can be done as $1 / 10$ to $1 / 12$ of bridge's span for single supported beams and for continuously supported beams as $1 / 14$ to $1 / 18$ or $1 / 20$ to $1 / 40$ for highway and for railway bridges, respectively.
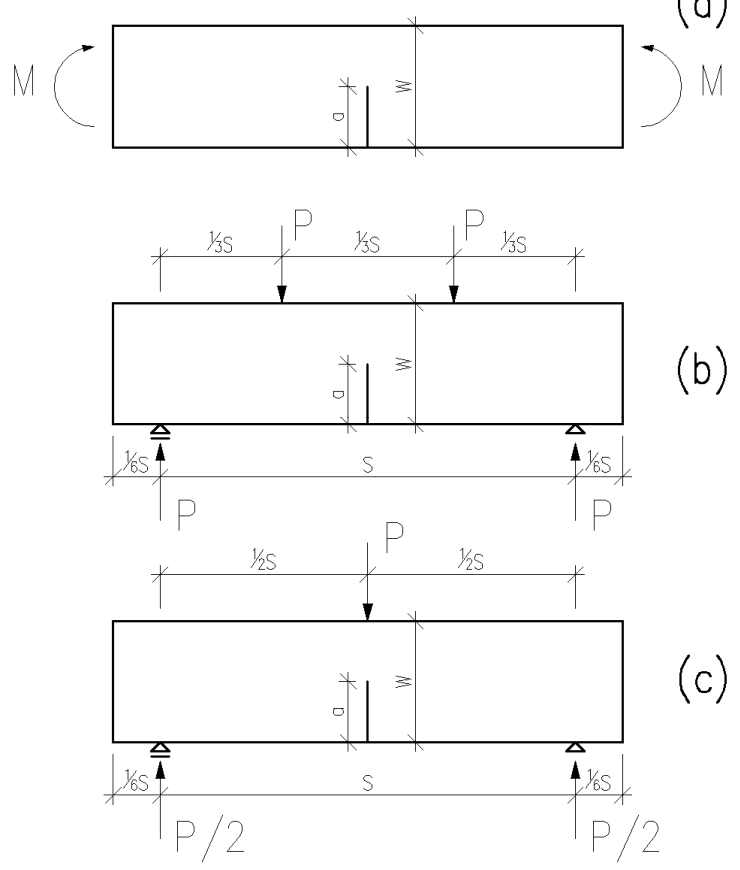

Fig. 1: Sketch of pure bending (a), four-point bending (b) and three-point bending (c).

Based on these empirical recommendations for beam's width a ratio of span to width $(S / W)$ is used. Following ratios were selected for the numerical calculation $S / W=10$ and 16 to cover, what was considered to be in a practical range.

\section{Numerical calculation}

In following sections an overview of numerical model and numerical results is presented. A finite element software ANSYS [27] for the numerical calculation was used.

\subsection{Material properties}

The crack propagation in steel structures is under small scale yielding condition, therefore the elastic properties of material were used as inputs for the finite element (FE) analysis [27]: e.g. Young's modulus and Poisson's ratio, $E=210 \mathrm{GPa}$ and $v=0.3$, respectively. 


\subsection{Numerical model}

The numerical model was created as a two-dimensional (2D) model with plane strain conditions. FE models were meshed with the element type PLANE183 and command KSCON was used in order to take into account the crack tip singularity (See Fig. 2), refined in the vicinity of the crack and the stress intensity factors were calculated from displacements of nodes at the crack tip by means of the implemented procedure KCALC according following equation:

$$
K_{I}=\sqrt{2 \pi} \frac{2 G}{1+\kappa} \frac{|v|}{\sqrt{r}}
$$

where $v$ is the nodal displacement, $G$ is the shear modulus, $\kappa$ is the Kolosov's constant for plane strain or plane stress boundary conditions and $r$ is the coordinate in the polar coordinate system.

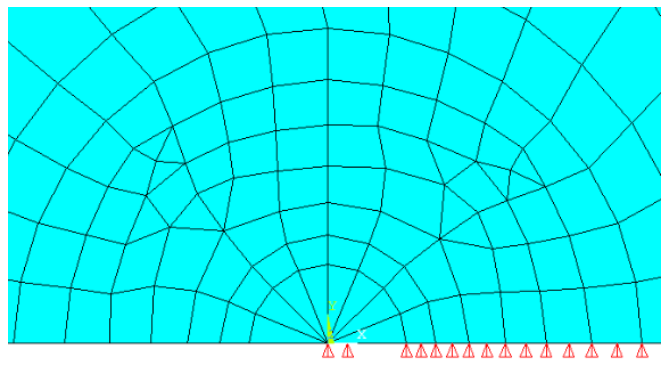

Fig. 2: Detail of the notch tip with shift of first node from crack tip to distance of $1 / 4$ length of element and used boundary conditions, detail is rotated $90^{\circ}$.

Numerical models were created as a half symmetric with sufficient boundary conditions. For three-point and four-point bending loads, models were loaded with force $P=100 \mathrm{~N}$ and the boundary condition as a support $u_{\mathrm{x}}=0$. The numerical model is shown in Fig. 3.

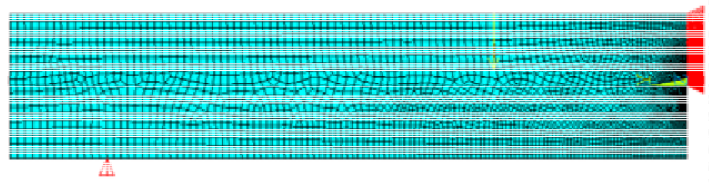

Fig. 3: Selected example of mesh and boundary conditions used for 4PB with ratio $S / W=8$.

Pure bending load was modelled as a half symmetric model with boundary conditions set to provide pure bending. The model was loaded with stress on the crosssection, which produces bending moment. The model was restricted from vertical movement at the neutral axis e.g. at $W / 2$ of the specimen (See Fig. 4) $u_{\mathrm{y}}=0 \mathrm{~mm}$. Such a boundary conditions provides numerical stability and demanded deformation of the specimen

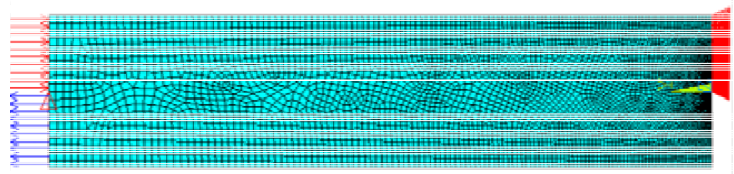

Fig. 4: Numerical model for pure bending load with ratio $S / W=8$.

\section{Results and discussion}

\subsection{Results from FEM}

The comparison of the obtained numerical results and several independent values extracted from the literature [16] and [17] for pure and three-point bending for $S / W=4$ is shown in Tab. 2. The data from presented study agrees well and proposed numerical model could be used in further analysis.

Tab. 2: Comparison of the presented geometry function with data from the literature.

\begin{tabular}{|c|c|c|c|c|c|c|}
\hline & \multicolumn{3}{|c|}{ Pure bending } & \multicolumn{3}{c|}{ Three-point bending } \\
\hline$a / W$ & $\begin{array}{c}\text { Tada } \\
{[16]}\end{array}$ & $\begin{array}{c}\text { Bakker } \\
{[17]}\end{array}$ & Present & $\begin{array}{c}\text { Tada } \\
{[16]}\end{array}$ & $\begin{array}{c}\text { Bakker } \\
{[17]}\end{array}$ & Present \\
\hline 0.1 & 1.043 & 1.047 & $\mathbf{1 . 0 5 3}$ & 1.007 & 0.980 & $\mathbf{0 . 9 8 1}$ \\
\hline 0.3 & 1.122 & 1.124 & $\mathbf{1 . 1 2 3}$ & 1.045 & 1.039 & $\mathbf{1 . 0 3 8}$ \\
\hline 0.5 & 1.495 & 1.498 & $\mathbf{1 . 4 9 5}$ & 1.416 & 1.406 & $\mathbf{1 . 4 0 4}$ \\
\hline
\end{tabular}

In the following part of obtained results, the dimensionless geometry functions with coefficient of determination $R^{2}$ are introduced. The range for relative crack length for each case was $a / W \in<0.01 \div 0.5>$. Three cases are selected: a) pure bending, b) TPB and c) FPB.

a) Pure bending moment (M):

$f(a / W)_{M}=1.1143-0.8975(a / W)+2.752(a / W)^{2}+1.1323(a / W)^{3}$ with $R^{2}=0.9992$.

\section{b) Three-point bending (TPB):}

$$
\begin{aligned}
& f(a / W)_{S / W=2}=1.0301-1.3702(a / W)+3.674(a / W)^{2}+0.4064(a / W)^{3} \text { with } R^{2}=0.9999 \\
& f(a / W)_{S / W=4}=1.0613-1.0638(a / W)+2.9774(a / W)^{2}+1.0418(a / W)^{3} \text { with } R^{2}=0.9992 \\
& f(a / W)_{S / W=8}=1.0887-0.9968(a / W)+2.9282(a / W)^{2}+1.0146(a / W)^{3} \text { with } R^{2}=0.9991 \\
& f(a / W)_{S / W=10}=1.0933-0.9647(a / W)+2.8372(a / W)^{2}+1.1064(a / W)^{3} \text { with } R^{2}=0.9992 \\
& f(a / W)_{S / W=16}=1.0994-0.9164(a / W)+2.7161(a / W)^{2}+1.2161(a / W)^{3} \text { with } R^{2}=0.9992 . \\
& f(a / W)_{S / W=40}=1.1093-0.9182(a / W)+2.7229(a / W)^{2}+1.1186(a / W)^{3} \text { with } R^{2}=0.9992
\end{aligned}
$$


$f(a / W)_{S / W=80}=1.1104-0.89(a / W)+2.6983(a / W)^{2}+1.2027(a / W)^{3}$ with $R^{2}=0.9992$.

\section{c) Four-point bending (FPB):}

$f(a / W)_{S / W=2}=1.2418-1.4507(a / W)+3.7652(a / W)^{2}+0.5241(a / W)^{3}$ with $R^{2}=0.9989$.

$f(a / W)_{S / W=4}=1.1449-0.954(a / W)+2.7378(a / W)^{2}+1.1984(a / W)^{3}$ with $R^{2}=0.9992$.

$f(a / W)_{S / W=8}=1.1146-0.8958(a / W)+2.7367(a / W)^{2}+1.152(a / W)^{3}$ with $R^{2}=0.9992$.

$f(a / W)_{S / W=10}=1.1126-0.8755(a / W)+2.6625(a / W)^{2}+1.236(a / W)^{3}$ with $R^{2}=0.9992$.

$f(a / W)_{S / W=16}=1.113-0.8801(a / W)+2.6791(a / W)^{2}+1.2181(a / W)^{3}$ with $R^{2}=0.9992$.

$f(a / W)_{S / W=40}=1.1126-0.8746(a / W)+2.659(a / W)^{2}+1.24(a / W)^{3}$ with $R^{2}=0.9992$.

$f(a / W)_{S / W=80}=1.1127-0.8748(a / W)+2.6584(a / W)^{2}+1.2412(a / W)^{3}$ with $R^{2}=0.9991$.

Fig. 5 compares the obtained geometry functions from FE analysis for various load types pure and three- and fourpoint bending and Fig. 6 compares pure and four-point for edge crack propagation. Various types of bending loads, mostly the ratio $S / W$ shows, that with increasing value a curve is shifting towards to the pure bending load.

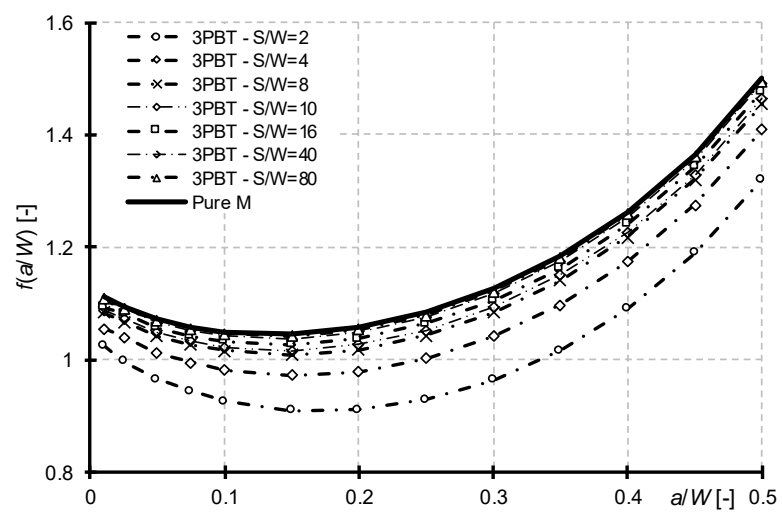

Fig. 5: Comparison of geometry functions for three-point bending loading configuration for various $S / W$ ratios.

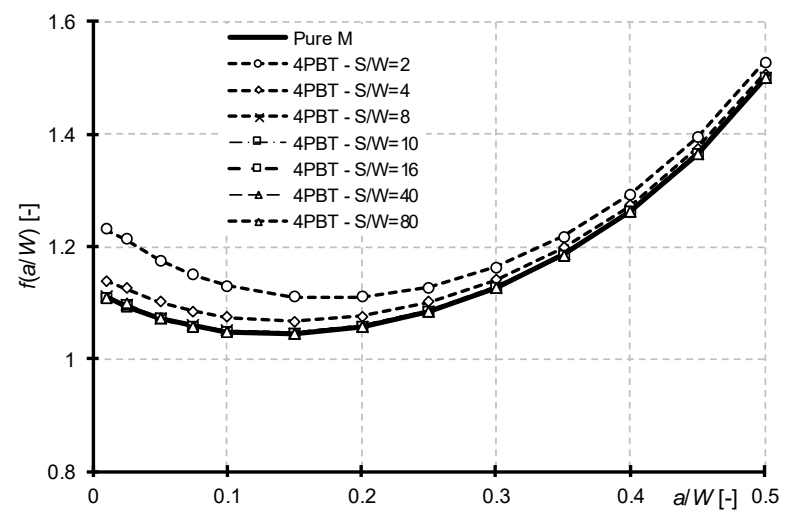

Fig. 6: Comparison of geometry functions for four-point bending loading configuration for various $S / W$ ratios.

Figs. 7-8 show plots of geometry functions against $S / W$ for constant ratio $a / W$ values of $0.1,0.3,0.4$ and 0.5 . In each case, the corresponding values of geometry function for pure bending are shown as a horizontal dashed line for comparison. The value for pure bending were taken from
Handbook (the same values in e.g. [16], [17], [18]) of course, are independent of $S / W$.

From Fig. 7 it is clear, that the value of geometry functions for three-point bend loading is always lower that for pure bending, but that difference decreases with increasing $S / W$. For example, in case $a / W=0.1$, the ratio of the geometry functions for pure and TPB loading is $0.982,1.016$ and 1.042 when $S / W=4,8,40$, respectively.

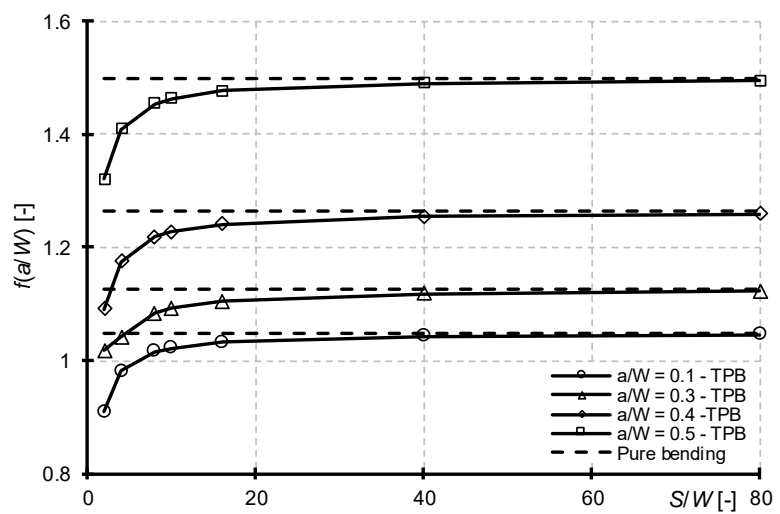

Fig. 7: Overview influence of the span length $(S / W$ ratio) on the geometry functions for three-point bending loading configuration for selected $a / W$ ratio.

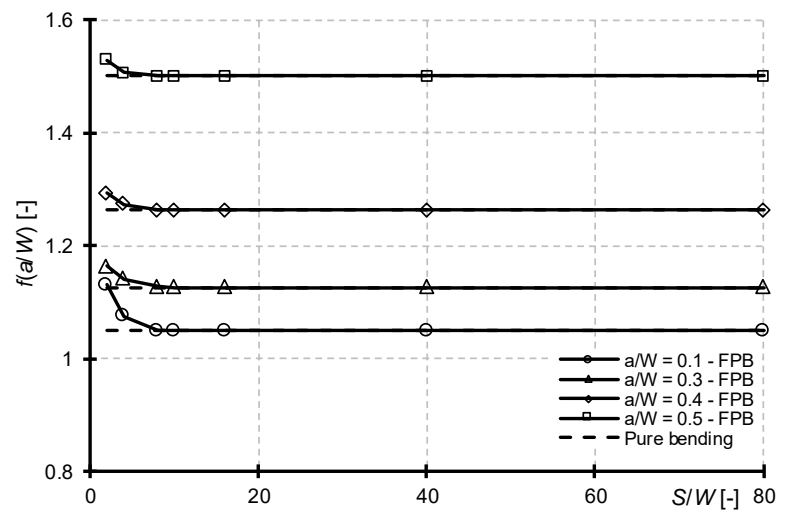

Fig. 8: Overview influence of the span length $(S / W$ ratio) on the geometry functions for four-point bending loading configuration for selected $a / W$ ratio.

It is obvious, from Fig. 8, that the value of geometry 
functions for four-point bending loading is always higher that for pure bending, but that difference decreases with increasing $S / W$ ratio. For example, in case $a / W=0.1$, the ratio of the calibration values for pure bending is 1.049 and for FPB loading is $1.074,1.050$ and 1.049 when $S / W=4$, 8 and 40 , respectively.

These facts should be considered for the prediction and evaluation of the structural residual fatigue life in standardly used method like in [4], [6], [8].

\section{Conclusion}

In this contribution, the results obtained by the numerical study (using KCALC command) are expressed in general form in terms of the dimensionless function of stress intensity factor. In case of pure bending, geometry functions are only a function of the relative crack length $a / W$, in study interval $<0.01 \div 0.5>$. In the cases of threeand four- point bend loading, the values are different from the corresponding values for pure bending, the difference is higher, when the ratio of support-span to specimen depth $S / W$. Thus, a different $K f(a / W)$ geometry functions are needed for each different value of $S / W$. Influence of various bending types on the geometry functions is presented. The proposed geometry functions were studied for short edge cracks and for the various span to width ratios. The proposed values of the geometry functions show good agreement with literature [16] and [17]. This effect should be considered in further fatigue design of steel structures.

As it is apparent from the values listed in Tab. 2, the analytical results does not differ fundamentally only with small error from the numerical calculations presented in this work. The same conclusion was also reached by the team of authors in work [15].

\section{Acknowledgements}

The authors acknowledge the support of Czech Sciences foundation project No. 17-01589S. This paper has been worked out under the "National Sustainability Programme I" project "AdMaS UP - Advanced Materials, Structures and Technologies" (No. LO1408) supported by the Ministry of Education, Youth and Sports of the Czech Republic and Brno University of Technology.

\section{References}

[1] KARMAZINOVA, M. Zakladni zasady navrhovani kovovych mostu, Modul M01 - Kovove Mosty I, Studijni opory, Brno, 2006 (in Czech).

[2] KREJSA, M., Z. KALA and S. SEITL. Inspection based probabilistic modelling of fatigue crack progression. Proceedia Engineering, 2016, vol. 142, pp. 145-152. DOI: 10.1016/j.proeng.2016.02.025.

[3] KREJSA, M., L. KOUBOVA, J. FLODR, J. PROTIVINSKY and Q.T. NGUYEN. Probabilistic prediction of fatigue damage based on linear fracture mechanics. Frattura ed Integrità Strutturale, 2017, vol. 11, nmr. 39, pp. 143-159. DOI: 10.3221/IGFESIS.39.15.

[4] KREJSA, M., J. BROZOVSKY, P. LEHNER, S. SEITL and Z. KALA. Stochastic analysis for short edge cracks under selected loads. AIP Conference Proceedings, 2018, 1978, 150006. DOI: 10.1063/1.5043797.

[5] KALA, Z. Identification of stochastic interactions in nonlinear models of structural mechanics. AIP Conference Proceedings, 2017, 1863, 480004. DOI: 10.1063/1.4992640.

[6] KALA, Z. and A. OMISHORE. Fuzzy stochastic approaches for analysing the serviceability limit state of load bearing systems. International. Journal of Mathematics and Computers in Simulation, 2016, vol. 10, pp. 294-301. ISSN: 1998-0159.

[7] CAStillo, E., A. CANTELI and D. SiEGELE, Obtaining S-N curves from crack growth curves: an alternative to self-similarity. International Journal of Fracture, 2014, vol. 187, nmr.1, pp. 159-172.

DOI: $10.1007 / \mathrm{s} 10704-014-9928-6$

[8] PYTTEL, B., A. CANTELI and A. RIPOLL. Comparison of different statistical models for description of fatigue including very high cycle fatigue. International Journal of Fatigue, 2016, vol. 93, pp. 435-442. DOI: 10.1016/j.ijfatigue.2016.04.019.

[9] CAStillo, E. and A. CANTELI. A general regression model for lifetime evaluation and prediction. International Journal of Fracture, 2001, vol. 107, pp. 117-137. DOI: 10.1023/A:1007624803955.

[10] SEITL, S., P. MIARKA, P. POKORNY, S. FINTOVA and J. KLUSAK. Influence of Micro-structure on the fatigue crack propagation in bridge steel. Proceedings, 2018, vol. 2, pp. 470.

DOI: $10.3390 /$ ICEM18-05373.

[11] KOCANDA, D., V. HUTSAYLYUK, T. SLEZAK, J. TORZEWSKI, H. NYKYFORCHY and V. KYRYLIV. Fatigue crack growth rates of S235 and S355 steels after friction stir processing. Materials Science Forum, 2012, vol. 726, pp. 203210.

DOI: 10.4028/www.scientific.net/MSF.726.203.

[12] DE JESUS, A.M.P., R. MATOS, B.F.C. FONTOURA, C. REBELO, L., SIMÕES DA SILVA and M. VELJKOVIC. A comparison of the fatigue behavior between S355 and S690 steel grades. Journal of Constructional Steel Research, 2012, 
$\begin{array}{lll}\text { vol. 79, pp. } & \text { 140-150. DOI: }\end{array}$ 10.1016/j.jcsr.2012.07.021.

[13] KRIVY, V., P. KONECNY. Real material properties of weathering steels used in bridge structures, Procedia Engineering. 2013, vol. 57, pp. 624-633. DOI: 10.1016/j.proeng.2013.04.079.

[14] SEITL, S., P. MIARKA, J. KLUSAK, S. FINTOVA and L. KUNZ, Comparison of the fatigue crack propagation rates in $\mathrm{S} 355 \mathrm{~J}$ and $\mathrm{J} 2$ steel grades, Key Engineering Materials, 2018, vol. 784, pp. 91-96. ISSN: $\quad 1662-9795 . \quad$ DOI: 10.4028/www.scientific.net/KEM.784.91

[15] SEITL, S., P. MIARKA, L., MALIKOVA and M., KREJSA. Comparison of calibration functions for short cracks under selected loads. Key Engineering Materials, 2017, vol. 754, pp. 353-356. ISSN: 16629795.

DOI:

10.4028/www.scientific.net/KEM.754.353.

[16] TADA, H., P.C. PARIS and G.R., IRWIN. The stress analysis of Cracks Handbook. New York, ASME international, 2000. DOI: 10.1115/1.801535.

[17] BAKKER. A.D. Evaluation of elastic fracture mechanics parameters for bend specimens. International Journal of Fracture, 1995, vol. 71, pp. 323-343. DOI: 10.1007/BF00037813.

[18] MURAKAMI. Y. Stress Intensity Factors Handbook. 1st Edition, Pergamon, 1986, ISBN:0080348092.

[19] GROSS, B. and J.E., SRAWLEY. Stress-Intensity factors for three-point bend specimens by boundary collocation. Nasa Technical note, NASA TN D-3092, 1965.

[20] FETT, T. Stress intensity factors and weight functions for special crack problems. Forschungszentrum Karlsruhe $\quad \mathrm{GmbH}, \quad$ Karlsruhe, 1998. http://digbib.ubka.unikarlsruhe.de/volltexte/fzk/6025/6025.pdf

[21] WILLIAMS, M.L. On the stress distribution at the base of a stationary crack. Journal of Applied Mechanics, 1957, 24, pp. 109-114. ISSN 0021-8936.

[22] WILLIAMS, M.L. The bending stress distribution at the base of a stationary crack. Journal of Applied Mechanics, 1961, vol. 28, pp. 78-82. DOI: 10.1115/1.3640470.

[23] PARIS, P.C. and F., ERDOGAN. A Critical Analysis of Crack Propagation Laws. Journal of Basic Engineering, 1963, vol. 85, pp. 528-533, DOI: 10.1115/1.3656900.

[24] KLESNIL, N. and P., LUKAS. Fatigue of metallic materials. Elsevier, 1992, vol 71, ISBN: 9780080934600.

[25] NASGRO: NASA Fatigue crack growth computer program version 3.0. Texas, 2000.

[26] CARPINTERI, A., B. CHIAIA and P. CORNETTI Three-Point Bending Test in Brittle Materials. Problems of Fracture Mechanics and Fatigue. Dordrecht, Springer, 2003, ISBN: 978-94-017-27747. DOI: 10.1007/978-94-017-2774-7_38.

[27] ANSYS User's manual version 17.2, 2016 www.ansys.com

\section{About Authors}

Stanislav SEITL was born in Přerov, Czech Republic. He received his habilitation (Assoc. prof.) from FCE BUT in 2015. His research interests include numerical simulation, fatigue and failure analysis and fracture-mechanical properties of civil engineering materials.

Petr MIARKA was born in Český Těšín, Czech Republic. He received his M.Sc. from FCE BUT in 2017. His research interests include numerical simulation, fatigue and failure analysis and fracture-mechanical properties of civil engineering materials.

Zdenek KALA was born Brno, Czech Republic. He received his title of professor from FCE BUT in 2008. His research interests include stochastic simulation, fatigue and failure analysis and fracture-mechanical properties of civil engineering materials. 